\author{
International Journal of Innovative Research in \\ Electrical, Electronics, Instrumentation and Control Engineering
}

Vol. 9, Issue 12, December 2021

DOI: $10.17148 / I J I R E E I C E .2021 .91202$

\title{
Aerodynamic analysis of wing with winglet using CFD
}

\author{
Ganesh $\mathbf{M}^{\mathbf{1}}$, Lavanya $\mathbf{R}^{2}$, Mahalakshmi $\mathrm{A}^{\mathbf{3}}$, Chandraleka G.K ${ }^{4}$, Sasiharan $\mathrm{P}^{\mathbf{5}}$ \\ Associate Professor, Aeronautical Engineering, Hindusthan College of Engineering and Technology, \\ Coimbatore, India ${ }^{1}$ \\ Student, Aeronautical Engineering, Hindusthan College of Engineering and Technology, Coimbatore, India 2,3,4,5
}

\begin{abstract}
Winglets being a small structure play an important role in reducing induced drag in an aircraft. The drag breakdown of a typical transport aircraft shows that the lift-induced drag can amount to as much as $40 \%$ of the total drag at cruise conditions and $80-90 \%$ of the total drag in take-off configuration. One way of reducing lift-induced drag is by using wingtip devices. GEO-777 specifications are taken to perform with a spiroid winglet. Indeed, the total drag count reduced with the help of winglets. A model composed of wing of boeing-777 is designed using CATIA and also the spiroid winglet are designed and attached with a boeing 777 wing using CATIA. Then the modelled wing is meshed using CFD. The meshed model will be analysed using ANSYS FLUENT. Finally, the difference in calculations is calculated using the analysis results.
\end{abstract}

Keywords: Winglet, Induced drag, Spiroid winglet, CATIA, CFD, ANSYS FLUENT.

\section{INTRODUCTION}

The flow of air over the surface of the airplane is the basic source of lifting or sustaining force that allow a heavier than air machine to fly. The shape of the airplane is designed to encourage the air flow over the surface to produce lifting force four fundamental quantities of aerodynamics are pressure, density, velocity and temperature. Winglets are considered as a powerful means of improving fuel efficiency for modern aircraft it increases the effective aspect ratio of wing without increasing structural loads. Winglet increase an aircraft operating efficiency by reducing induced drag at the tip of the wings. A wing's aerodynamic efficiency is expressed as its lift-to-drag ratio the list of a wing generate at a given speed and angle of attack can be one to two orders of magnitude greater than the total drag on the wing. The rules of aerodynamics explain how an airplane is able to fly.

In this literature of optimal solutions are constructed for weight and drag, which are competing objectives in the context of wing design. Three winglet configurations are considered: winglet-up, winglet-down, and raked wingtips. These are compared to optimized planar wings of the same span [1]. Hereby considered the Winglet is considered with ability of in-flight shape changing and optimisation process is focused to revealing of optimal shapes for different flight regimes Wing and winglet parametric CAD model description is followed by CFD model creation process and CFD simulation pre-processing description [2]. There they defined the small fins or vertical extensions at the end of the wing known as wing tips. Winglet improves the aircraft efficiency by reducing induced drag which is being caused by the vortices generated at the tip of the wing [3].

They have done design and analysis of spiroid winglet for drag reduction. The study consists of designing and analysing of spiroid model and carrying out the Computational Fluid Dynamics simulation to simulate the spiroid winglet design having significant aerodynamic performance [4]. Here they have noticed at low speeds to find out the most suitable aerofoil design to be used in the low-speed aircrafts. The numerical simulation of low speed and high- lift aerofoil has been done using ANSYSFLUENT to obtain drag coefficient, lift coefficient, coefficient of moment and Lift-to-Drag ratio over the aerofoils for the comparative analysis of aerofoils [5]. The aim of this Project is to reduce the aircraft's drag by partial recovery of the tip vortex energy. it is obvious that the results of the wing with the spiroid winglet have overall better aerodynamic characteristics then the aerodynamics characteristics of wing model alone [6]. In their project focuses the investigation of aerodynamic characteristics of a wing model with RGV winglet. A computational fluid dynamics (CFD) study using ANSYS 15.0 was conducted to study the effect of the RGV winglet on a rectangular wing [7]. 
International Journal of Innovative Research in Electrical, Electronics, Instrumentation and Control Engineering

Vol. 9, Issue 12, December 2021

DOI: 10.17148/IJIREEICE.2021.91202

\section{COMPUTATIONAL METHODOLOGY}

Finite Element Analysis

\subsection{CATIA:}

Open CATIA. File -> select and open the saved aerofoil coordinates of GOE777 in the form of xlsx. Give ok, the aerofoil coordinate will generate join the coordinates.

Mechanical design-> wireframe and surface design pad /extrude the aerofoil along the direction and offset it.

Part design draw aerofoil along the tip chord of the wing then select plane. Pad -> off setup to 14 planes (30 degree) to get spiroid winglet shape.

\subsection{MESHING:}

The CAD drawings made using CATIA was imported to ICEM CFD. The imported files are in *stp format. The parts are created in geometry phase. Parts named as INLET, OUTLET, WALL, WING and BODY. Meshing was made using unstructured tetrahedral mesh tool. Then the solver option and output options were converted to ANSYS CFX formats and exported to *.cfx format.

\subsection{DESIGN GEOMETRY}

Design geometry: B777 wing

Wing length $: 63.7 \mathrm{~m}$

Aerofoil : gottingen777(GOE777-il)

Wing span : $64.8 \mathrm{~m}$

Max thickness : $22 \%$

Max chord : $: 30 \%$

Max camber $: 5.9 \%$

Aspect ratio $\quad: 9.8$

Spiroid winglet

Aerofoil : NACA 0012

Angle : 30 degrees

Winglet Height: $3 \mathrm{~m}$

Chord length $: 2 \mathrm{~m}$

Max thickness : $12 \%$

Max chord : $30 \%$

\section{MESH PARAMETERS}

Mesh type : : Unstructured mesh

Inflation: Smooth

Smoothing: Medium

Model: viscous (laminar flow)

Maximum layers: 5

Growth rate: 1.2

Nodes:31107

Element size: 15

Active Bodies: 2

Elements:110299

Boundary box diagonal: $22.344 \mathrm{~mm}$

\subsection{BOUNDARY CONDITIONS}

The boundary condition for both the normal wing and Spiroid winglets are:

Viscous mode - k omega

Inlet velocity $-150 \mathrm{~m} / \mathrm{s}$

Transition ratio- 0.212

Interior, solid

Outlet pressure - 19000 pa

Wall (solid) - stationary wall

Velocity specification - Magnitude and direction 


\section{IJIREEICE}

International Journal of Innovative Research in

Electrical, Electronics, Instrumentation and Control Engineering

Vol. 9, Issue 12, December 2021

DOI: 10.17148/IJIREEICE.2021.91202

III. RESULT AND DISCUSSION

\subsection{VS ITERATION}

The $\mathrm{C}_{\mathrm{L}}$ value increases from -0.0000 to 0.0000 between the iteration of 5 to 10 and then decreases and maintain the constant lift force.

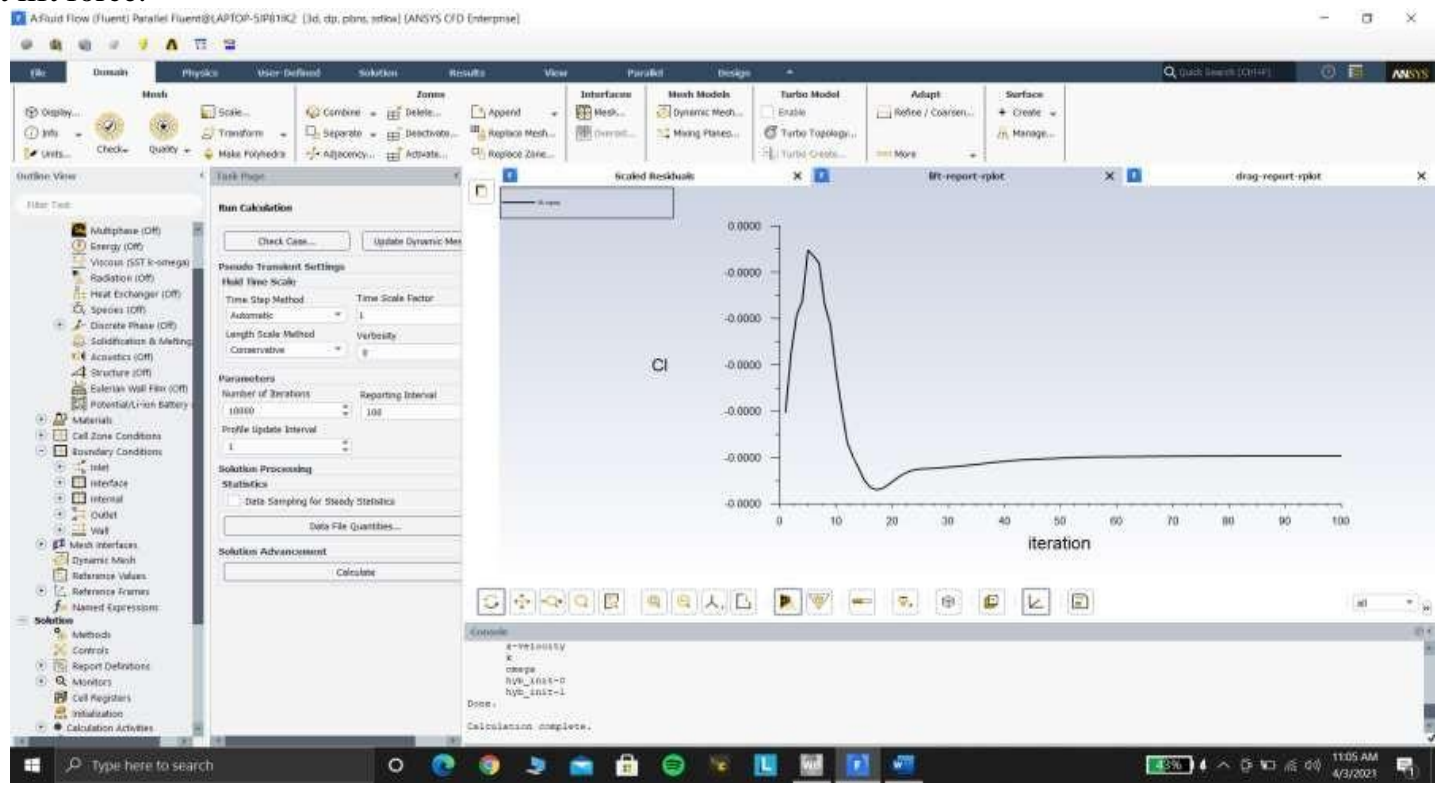

Fig.1. $C_{L}$ vs Iteration

\section{2 $\mathrm{C}_{\mathrm{D}}$ VS ITERATION}

The $C_{D}$ value of -0.0000 at iteration 1 is maintained constant drag reduction throughout the 100 iterations.

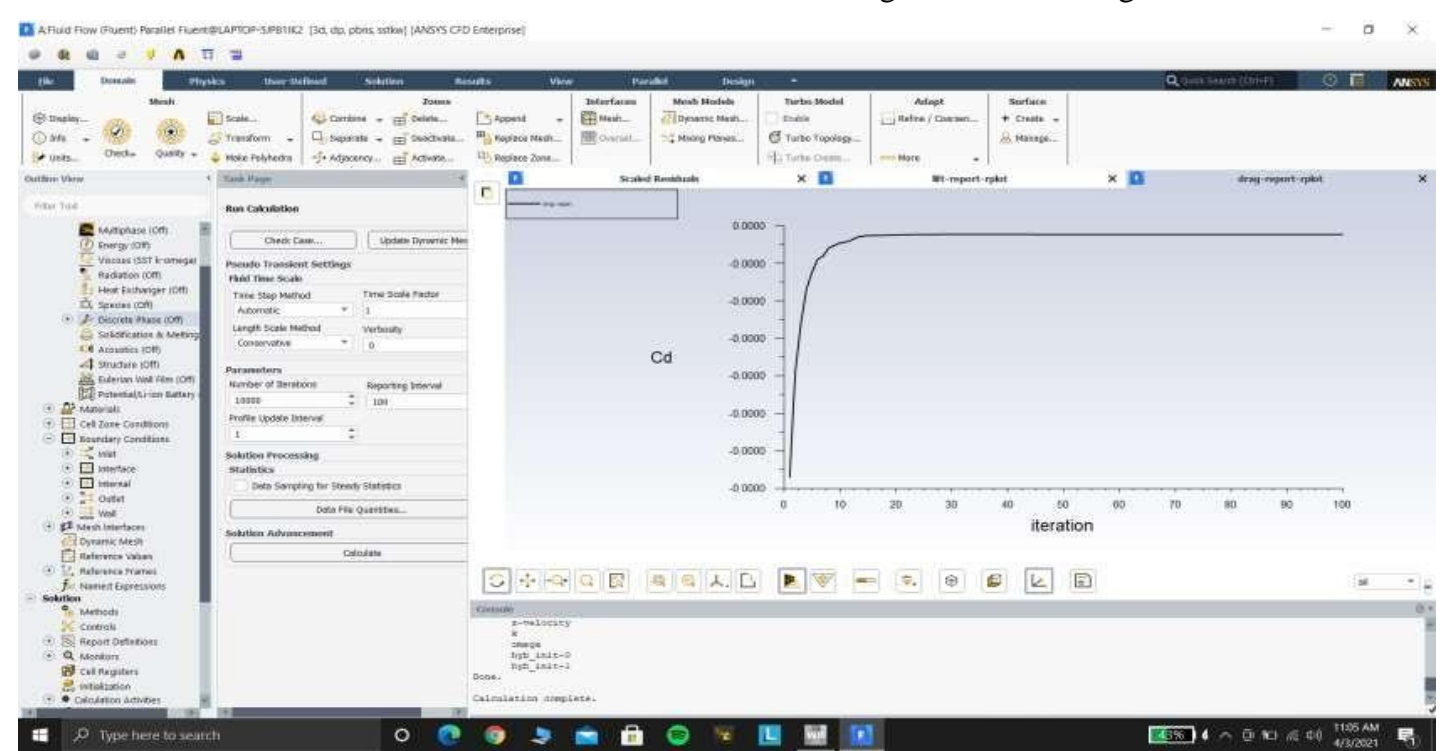

Fig.2. $C_{D}$ vs Iteration

\subsection{CONTINUITY, XYZ, K, OMEGA VS ITERATION}

For $\mathrm{v}=150 \mathrm{~m} / \mathrm{s}$. the continuity of $1 \mathrm{e}+00$ is observed in scaled residuals for iteration $100, \mathrm{x}, \mathrm{y}, \mathrm{z}$, velocities lie between $1 \mathrm{e}-$ 00 to $1 \mathrm{e}-01$. 
International Journal of Innovative Research in Electrical, Electronics, Instrumentation and Control Engineering

Vol. 9, Issue 12, December 2021

DOI: $10.17148 /$ IJIREEICE.2021.91202

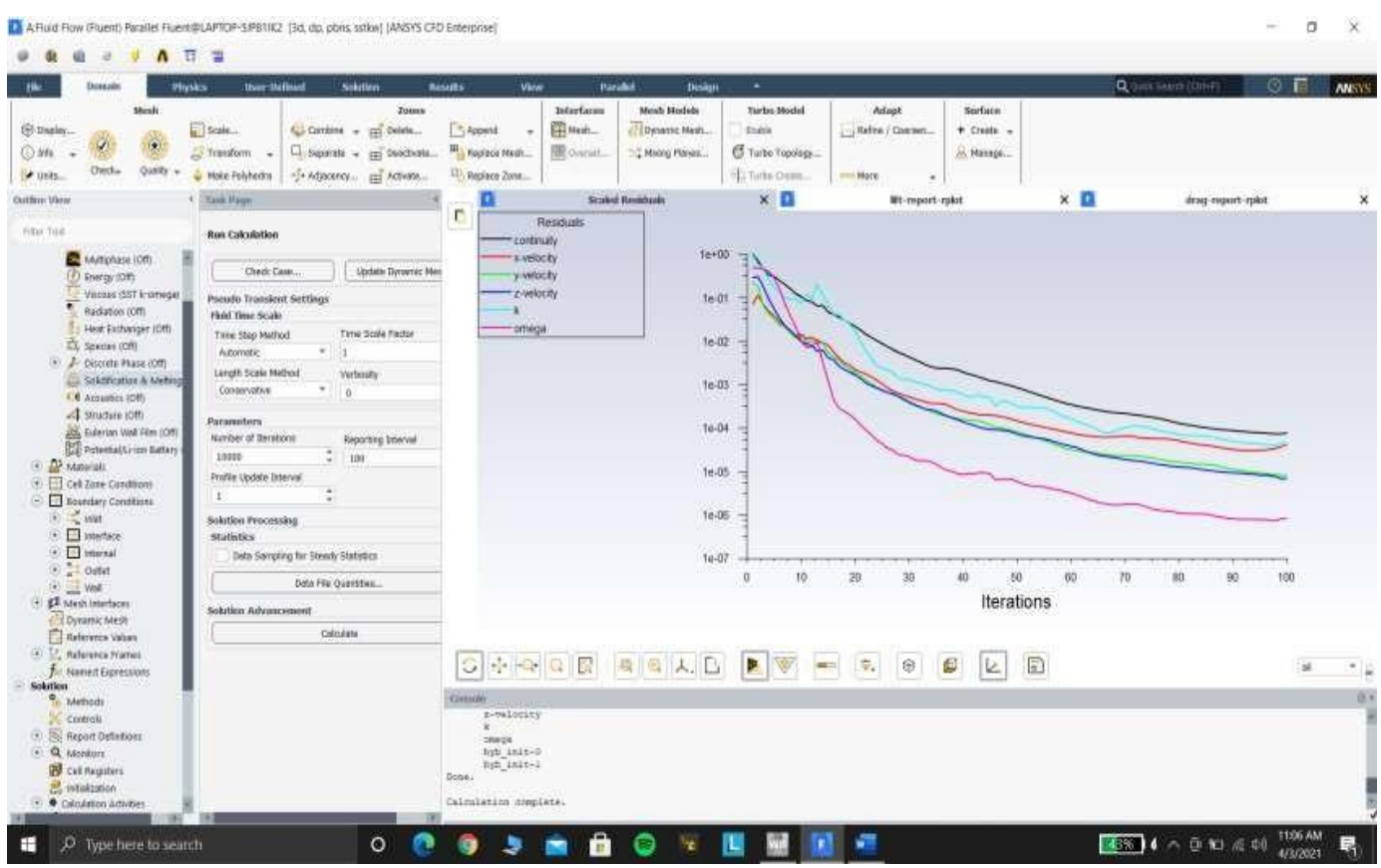

Fig.3. Continuity, xyz, k, Omega vs Iteration

\section{CONCLUSION}

- In the aeronautical field reducing drag is a major challenge, in this regard for reducing induced drag we used spiroid winglet.

- If lift to drag ratio increases the drag will reduce here in this spiroid winglet.

- One way of reducing lift-induced drag is by using winglet devices by applying biomimetic abstraction of the principle behind a bird's wingtip feathers, we study spiroid winglet which look like an extended blunded winglet that bends upward by 360 degrees to form a large rigid ribbon.

- Therefore, to increase the lift and reduces the induced drag at cruise condition and tosave the airline fuel, the wing with spiroid winglets is used.

\section{REFERENCES}

[1]. A Numerical Optimization Study on Winglets Global Science and Technology Journal Vol.3. No. 1. March 2015 Issue. Shahriar Khosravi* and David W.Zingg Institute for Aerospace Studies, University of Toronto.

[2]. Aerodynamic Analysis of Morphing Geometry Application to Sailplane Winglet Design BRNO 2017 AERODYNAMICKÁ ANALÝZA MĚNITELNÉ GEOMETRIE WINGLETU PRO APLIKACI NA VÝKONNÉM KLUZÁKU.

[3]. Aerodynamics of Winglet: a Computational Fluid Dynamics Study Md. Saifuddin Ahmed Atique1, Md. Abdus Salam2, Asif Shahriar Nafi3, Nafisa Nawal Probha4 and Shuvrodeb Barman*5Global Science and Technology Journal Vol. 3. No. 1. March 2015 Issue.

[4]. DESIGN AND ANALYSIS OF SPIROID WINGLET FOR DRAG REDUCTION, Volume 4, Issue 9, September -2019 International Journal of Innovative Science and Research Technology.

[5]. An Aerodynamic Comparative Analysis of Airfoils for Low-Speed Aircrafts Sumit Sharma. International Journal of Engineering Research \& Technology,Vol. 5 Issue 11, November-2016.

[6]. Contrive and Analysis of Spiroid Winglet for Drag Contraction. International Journal for Research in Applied Science \& Engineering Technology, Volume 8 Issue IVApr 2020.

[7]. Investigation of Aerodynamic Characteristics of a Wing Model with RGVWinglet Sivaraj Gopal Krishnan, Mohammad Hafifi Ishak, Mohammad Azwan Nasirudin, Farzad Ismail, * Krishnan SG Ishak MH Nasirudin MA Ismail F. 